\title{
ASO Author Reflections: Essential to Reduce Adverse Outcomes in Perihilar Cholangiocarcinoma Surgery-Portal Vein Embolization
}

\author{
Pim B. Olthof, MD, $\mathrm{PhD}^{1,2}$, and Thomas M. van Gulik, $\mathrm{MD}, \mathrm{PhD}^{1}$ \\ ${ }^{1}$ Department of Surgery, Amsterdam UMC (Location AMC), University of Amsterdam, Amsterdam, The Netherlands; \\ ${ }^{2}$ Department of Surgery, Erasmus Medical Center, Rotterdam, The Netherlands
}

\section{PAST}

Major liver resection for perihilar cholangiocarcinoma is associated with 90-day mortality rates of up to $18 \%$ in Western series. ${ }^{1}$ Posthepatectomy liver failure is the primary cause of the high perioperative mortality. ${ }^{2}$ However, the golden standard preoperative procedure to reduce liver failure and mortality - portal vein embolization-is sparsely used in Western centers for patients with perihilar cholangiocarcinoma. ${ }^{3,4}$ This is in contrast to Eastern centers, where application of portal vein embolization is liberal and mortality rates are lower. ${ }^{3}$

\section{PRESENT}

Our recent paper shows that application of preoperative portal vein embolization before major liver resection for perihilar cholangiocarcinoma is associated with marked reductions in posthepatectomy liver failure and 90-day mortality rates. Using data of 1667 patients from 20 centers, a propensity score matched comparison was performed. In the matched cohort, liver failure and

This ASO Author Reflections is a brief invited commentary on the article, "Portal Vein Embolization Is Associated with Reduced Liver Failure and Mortality in High-Risk Resections for Perihilar Cholangiocarcinoma," Ann Surg Oncol. (2020). https://doi.org/10. 1245/s10434-020-08258-3.

(C) The Author(s) 2020

First Received: 25 February 2020;

Published Online: 9 March 2020

P. B. Olthof, MD, PhD

e-mail: p.b.olthof@amc.nl mortality rates were $8 \%$ and $7 \%$, respectively, with resection after portal vein embolization, compared with $36 \%$ and $18 \%$, respectively, after resection without portal vein embolization $(P<0.001$ and $P=0.031){ }^{4}$ Although these results might be expected, these analyses have not been performed previously in a cohort with resections for only perihilar cholangiocarcinoma. The disease most often requires major liver resection as well as extrahepatic bile duct resection, which alone is high-risk surgery. But these patients often suffer from obstructive jaundice requiring biliary drainage, which can induce cholangitis and further increase the risk of adverse outcomes.

\section{FUTURE}

Perihilar cholangiocarcinoma is rare, and solid research on the optimal treatment strategy is difficult. In our opinion, a randomized trial on the effect of portal vein embolization is not required and perhaps unethical in light of the currently available evidence. Future studies should focus on the optimal indications for portal vein embolization. The goal is to provide a curative resection to as many patients as possible, while reducing the risks of adverse outcomes to a minimum. The balance between these two is a challenge for future studies. Perhaps alternative techniques such as quantitate liver function assessment can help to select those patients who will especially benefit from portal vein embolization. ${ }^{5}$

DISCLOSURES The authors report no conflicts of interest.

OPEN ACCESS This article is licensed under a Creative Commons Attribution 4.0 International License, which permits use, sharing, adaptation, distribution and reproduction in any medium or format, as long as you give appropriate credit to the original author(s) and the source, provide a link to the Creative Commons 
licence, and indicate if changes were made. The images or other third party material in this article are included in the article's Creative Commons licence, unless indicated otherwise in a credit line to the material. If material is not included in the article's Creative Commons licence and your intended use is not permitted by statutory regulation or exceeds the permitted use, you will need to obtain permission directly from the copyright holder. To view a copy of this licence, visit http://creativecommons.org/licenses/by/4.0/.

\section{REFERENCES}

1. Franken LC, Schreuder AM, Roos E, et al. Morbidity and mortality after major liver resection in patients with perihilar cholangiocarcinoma: a systematic review and meta-analysis. Surgery. 2019;165(5):918-28.

2. Olthof PB, Wiggers JK, Groot Koerkamp B, et al. Postoperative liver failure risk score: identifying patients with resectable perihilar cholangiocarcinoma wWho can benefit from portal vein embolization. J Am Coll Surg. 2017;225(3):387-94.

3. Olthof PB, Miyasaka M, Koerkamp BG, et al. A comparison of treatment and outcomes of perihilar cholangiocarcinoma between Eastern and Western centers. HPB (Oxford). 2019;21(3):345-51.

4. Olthof PB, Aldrighetti L, Alikhanov R, et al. Portal vein embolization is associated with reduced liver failure and mortality in high-risk resections for perihilar cholangiocarcinoma. Ann Surg Oncol. 2020. https://doi.org/10.1245/s10434-020-08258-3.

5. Olthof PB, Coelen RJS, Bennink RJ, et al. (99m)Tc-mebrofenin hepatobiliary scintigraphy predicts liver failure following major liver resection for perihilar cholangiocarcinoma. HPB (Oxford). 2017;19(10):850-58.

Publisher's Note Springer Nature remains neutral with regard to jurisdictional claims in published maps and institutional affiliations. 